\title{
A atualidade de Pierre Monbeig e o direito de aprender Geografia ${ }^{1}$
}

\section{Maria Eliza Miranda ${ }^{2}$}

"Só os geógrafos estavam firmes, com seus sete mil representantes. Mas, é claro, era uma ciência de grande duração..." ${ }^{3}$

\begin{abstract}
Resumo: Este artigo destaca as contribuições de Pierre Monbeig para a reflexão contemporânea acerca do valor do ensino de geografia na educação escolar. Discute aproximações entre estas contribuições e outras tendências que também abordam a importância da escola e o valor do ensino de geografia para a formação do pensamento crítico e o desenvolvimento das funções intelectuais de futuras gerações. Destaca a relação que o próprio autor estabelece entre suas concepções de geografia e de ensino, as quais permanecem centrais no debate contemporâneo sobre as perspectivas da ciência geográfica diante dos dilemas que envolvem a formação do geógrafo e professor de geografia. Assinala a preocupação com a qualidade tanto do ensino de geografia quanto da formação do professor. Aponta ainda a necessidade de superação do isolamento existente entre a formação do geógrafo e a do professor de geografia, devido à tendência de expansão de cursos de licenciatura, com variadas cargas horárias e estruturas curriculares, que, em geral, não tem assegurado o pleno domínio do pensamento científico e acadêmico do professor de geografia, não sem efeitos negativos na formação dos estudantes da escolarização básica e também na difusão do valor e da importância do trabalho do geógrafo na sociedade.
\end{abstract}

Palavras-chave: Geografia; Ensino; Professor; Ciência; Crítica.

\section{Pierre Monbeig is still present and the right of learning Geography}

Abstract: This article highlights Pierre Monbeig's contributions in order to think about the contemporary value of teaching Geography in school. It discusses the similarities between those contributions and other trends that also deals with the importance of studying and the value of teaching Geography not only to the formation of future generations' critical thinking but also to the development of their intellectual functions. It stands out the relationship that author established between their conceptions of Geography and Education, which remain central to the contemporary debate on the expectations of Geographical science when facing dilemmas involving the formation of the geographer and the Geography teacher too. It presents concernment to the quality of teaching Geography and that one of training Geography teachers. It reinforces the need to overcome the isolation that still exists between both the geographer and Geography teacher's formation, due to the tendency of expanding courses degree, with varied workloads and curricular structures, which in general has not

\footnotetext{
${ }^{1}$ Todas as referências acerca do pensamento de Pierre Monbeig utilizadas foram encontradas no artigo Papel e Valor do Ensino da Geografia e de sua Pesquisa de Pierre Monbeig publicado pelo IBGE - Conselho Nacional de Geografia em 1956. As citações feitas aqui do texto deste autor terão a indicação no rodapé, das páginas da versão impressa desta publicação sobre a qual trabalhamos, mas cujo artigo se encontra disponível (com algumas alterações) também no formato digital em PDF no sítio que segue: http://www.epublicacoes.uerj.br/index.php/tamoios/article/view/609/641

${ }^{2}$ Bacharel e Licenciada em História e Geografia pela Universidade de São Paulo, mestre e doutora em Ciências Geografia Humana pela Universidade de São Paulo. Docente e pesquisadora da área de Licenciatura do Departamento de Geografia da Faculdade de Filosofia, Letras e Ciências Humanas da Universidade de São Paulo. E-mail: elizamir@usp.br

${ }^{3}$ DAVIDTS, Jean-Pierre. A Volta do Pequeno Príncipe. Ediouro. Rio de Janeiro. 1999. pp. 65.
} 
assured Geography teachers who works at school to completely master scientific and academic thinking, causing negative effects on regular students' schooling process, on geographers' value and also on the importance of their work to society.

Key-Words: Geography; Education; Teacher; Science; Criticism.

\section{INTRODUÇÃO}

Este artigo tem por objetivo refletir sobre a contribuição do pensamento de Pierre Monbeig para se repensar o ensino de geografia contemporâneo, por ocasião da comemoração dos 30 anos da Revista do Departamento de Geografia da Universidade de São Paulo.

Sendo Monbeig um dos precursores e formadores do pensamento geográfico brasileiro, considerando seu relevante papel na própria consolidação do curso de Geografia da Universidade de São Paulo, pretendemos examinar sua visão a respeito do ensino de geografia na educação escolar no sentido de refletir sobre sua atualidade também sobre o valor da ciência geográfica enquanto uma ciência humana.

Cabe esclarecer que consideramos aqui a problematização sugerida por Jean Piaget quanto à concepção de ciências humanas, quando considerou na década de 1970, as dificuldades em relação a se estabelecer um princípio de classificação das ciências do homem afirmando

[...] Limitemo-nos, neste ponto, assinalar que é difícil distinguir diferenças de natureza entre aquilo que se designa muitas vezes por "ciências sociais" e as "ciências humanas", porque é evidente que os fenômenos sociais dependem de todos os caracteres do homem, inclusive os processos psicológicos, e que, reciprocamente, as ciências humanas são todas sociais, por um ou por outro dos seus aspectos. A distinção só faria sentido (e é esta a hipótese que está na sua origem) se pudéssemos dissociar no homem aquilo que provém das sociedades particulares em que vive e o que constitui a natureza universal. ${ }^{4}$

Pierre Monbeig apontou na década de 50 do século passado a tendência de afirmação do que é a Geografia em detrimento do seu valor no ensino ${ }^{5}$, assinalou também, assim como ocorre, de certo modo atualmente, que o público culto não acompanha o progresso da ciência geográfica, quando até ignora sua existência (MONBEIG, 1956). Estabeleceu uma posição crítica em relação ao uso excessivo de memorização no ensino de Geografia, não ignorando a relevância das funções da memória nos processos de ensino e aprendizagem, as

\footnotetext{
${ }^{4}$ PIAGET, Jean. A Situação das Ciências do Homem no sistema das Ciências. Livraria Bertrand, Lisboa. 1976. pp.17.

${ }^{5}$ Certas expressões emprestadas do próprio texto de Pierre Monbeig aparecem em itálico quando incorporadas no corpo de nosso texto.
} 
quais se revestem de uma importância crucial no debate contemporâneo sobre o ensino e a educação em geral.

Identificou que o ensino de Geografia pode contribuir para a expansão das funções intelectuais dos jovens, pensando também no papel e na importância da escola e do professor de Geografia na sociedade. Apresentou de modo sintético uma concepção de escola e uma determinada concepção de currículo na qual ocupa lugar central o conhecimento e sua relação com o desenvolvimento do ser humano quando afirmou

[...] que o ensino de geografia é passível de auxiliar a expansão das funções intelectuais dos jovens. Deve ficar bem claro ser esse o papel fundamental do ensino secundário. Enviamos nossos filhos às escolas não somente para que encham suas cabeças, mas principalmente para que o façam bem. Esperamos dos professores que ensinem a nossos filhos e filhas literatura, matemática, línguas mortas ou vivas, história, geografia, ciências físicas e naturais, mas também exigimos que estes professores lhes desenvolvam as faculdades intelectuais ainda embrionárias. Da mesma forma que o treinador de desportos põe os músculos em condições de trabalho, o professor, treinador espiritual, tem o terrível encargo de lhes ensinar a observar, refletir, criticar e escolher. Aquilo que, no ensino, não permitisse desenvolver essas faculdades mereceria ser abolido dos programas sem o menor escrúpulo. Vamos tentar demonstrar como a geografia responde às exigências dum ensino que mais procura formar a mente do que entulhar cérebros (grifos nossos). ${ }^{6}$

É interessante destacar que o autor considerava amplos aspectos do processo de desenvolvimento do ser humano, quando exige que os professores ensinem a nossos filhos $e$ filhas os conhecimentos em geral, mas também propiciem o desenvolvimento de suas faculdades intelectuais, determinando assim uma importante finalidade da escola, que interessa muito pensar atualmente, que é o papel da escola para também apoiar o desenvolvimento das faculdades intelectuais, dentre as quais destacamos a iniciação da criança e do adolescente no sistema de conceitos, conforme encontramos em Vigotski, que, aliás muito antes de Monbeig, a esse respeito assim se expressou:

O desenvolvimento dos conceitos científicos na idade escolar é, antes de tudo, uma questão prática de imensa importância - talvez até primordial do ponto de vista das tarefas que a escola tem diante de si quando inicia a criança no sistema de conceitos científicos. Por outro lado, o que sabemos sobre esta questão impressiona pela pobreza. É igualmente grande a importância teórica dessa questão, uma vez que o desenvolvimento dos conceitos científicos - autênticos, indiscutíveis, verdadeiros - não pode deixar de revelar no processo investigatório as leis mais profundas e essenciais de qualquer processo de formação de conceitos em geral. ${ }^{7}$

\footnotetext{
${ }^{6}$ Pág. 16.

${ }^{7}$ VIGOTSKI, L. S. A construção do pensamento e da linguagem. Editora WMF Martins Fontes. São Paulo. 2009. pp. 241.
} 
Monbeig também sublinhou já em sua época, a questão de gênero humano, antes mesmo da expansão deste debate, tão caro hoje em dia, na sociedade brasileira. Isto é relevante, pois já enfatizava a importância da escolarização tanto da população masculina quanto feminina, cujos desdobramentos são muito significativos na sociedade contemporânea.

Cabe ressaltar ainda que, ao afirmar que aquilo que, no ensino, não permitisse desenvolver essas faculdades [intelectuais] mereceria ser abolido dos programas sem o menor escrúpulo, Monbeig adotou uma posição radical em prol de uma didática para o ensino de Geografia cuja centralidade estaria relacionada ao processo da aprendizagem e não apenas ao conteúdo a ser ensinado. E isto por si só também é muito atual, já que vivemos um momento em que a questão do desenvolvimento e da aprendizagem no debate educacional persiste, inclusive devido à contribuição dos avanços da psicologia, da neurociência, da ciência da informação e das ciências tecnológicas.

Há aqui a possibilidade de aproximação da posição de Monbeig com as concepções de Edgar Morin também, quando este nos remete a Montaigne que afirmou que "mais vale uma cabeça bem-feita que bem cheia". Morin (2008, p.21) nos lembra de que...

[...] O significado de uma "cabeça bem cheia" é óbvio: é uma cabeça onde o saber é acumulado, empilhado, e não dispõe de um princípio de seleção e organização que the dê sentido. "Uma cabeça bem-feita" significa que, em vez de acumular o saber, é mais importante dispor ao mesmo tempo de: uma aptidão geral para colocar problemas e tratar os problemas; $[e]$ princípios organizadores que permitam ligar os saberes e lhes dar sentido. [...] É evidente que isso não pode ser inserido em um programa, só pode ser impulsionado por um fervor educativo. ${ }^{8}$

Se considerarmos o contexto em que viveu e escreveu sobre o ensino de Geografia na escola, situamos Monbeig atualizado e observador arguto de seu tempo sobre os avanços das pesquisas lideradas por Piaget que já havia, desde a primeira metade do século XX, impulsionado as concepções sobre a estrutura do pensamento e formulado sua teoria do desenvolvimento humano, e cujas ideias revolucionaram as concepções de epistemologia, fundando a epistemologia genética a qual considera que o potencial cognitivo humano se desenvolve após o nascimento, tendo que se aprender a pensar, o que acontece também nas interações e relações com o meio.

Demonstrando compreender o potencial cognitivo humano e a natureza dos processos operatórios nele envolvidos, Monbeig demonstra assim que não considerava a

\footnotetext{
${ }^{8}$ MORIN, Edgar. A cabeça bem-feita - repensar a reforma, reformar o pensamento. Bertrand Brasil, Rio de Janeiro. 2008 . pp.21 e 22.
} 
criança e o adolescente como adultos em miniatura, ideia que contraria as concepções inatistas sobre o ser humano, levando em consideração o processo de desenvolvimento de crianças e adolescentes relacionando-o às etapas de escolarização e afirma que

[...] em todas as séries escolares, mas, sobretudo nas primeiras, o professor de geografia deve procurar desenvolver nos alunos o espírito de observação e de precisão. O resultado é facilmente obtido acostumando-se a criança a examinar e explicar com atenção uma carta, por mais simples que seja uma figura, uma projeção fotográfica. $\mathrm{O}$ aluno deve ser exercitado progressivamente a localizar com precisão e descrever o documento que Ihe é apresentado. Não seria conveniente que esse documento fosse muito científico e complicado. Deve-se, ao contrário, limitar-se ao menos no começo, a oferecer somente cartas e figuras muito simples, pedindo aos alunos que descrevam primeiro os principais elementos. Somente depois disso se poderá passar às minúcias e finalmente será possível arriscar-se a fazer os alunos descobrirem e exporem as relações existentes entre diferentes fatos anteriormente conhecidos, descritos e identificados [...]. É, portanto nesse sentido que se deve dirigi-lo, conduzindo-o progressivamente a adquirir uma visão de conjunto completada pela precisão da descrição [...]. Não é necessário dizer-se que esse treinamento não deve ser reservado exclusivamente aos alunos mais novos. Convém adotá-lo até nas últimas classes colegiais. Para evitar a monotonia e, aproveitando o crescente amadurecimento intelectual dos alunos, os professores apresentarão os documentos mais complexos e procurarão obter observações cada vez mais agudas. [...] Não só à faculdade de observação aproveita o ensino da geografia, mas também ao espírito crítico, pois o jovem interrogado sobre uma carta ou uma fotografia é obrigado a escolher entre o essencial e o secundário. Aprende assim a raciocinar com método e exercitar-se na escolha dos dados apresentados à sua observação. Ao mesmo tempo sua mente habitua-se a reconhecer as relações entre os fatos." (grifos nossos). ${ }^{9}$

Em que pese o estilo do texto e o gênero discursivo de enunciação de suas ideias, na longa citação que apresentamos, Monbeig trata, na verdade, de diversos temas de interesse que permanecem muito atuais na discussão contemporânea sobre a natureza do ensino e da aprendizagem, como por exemplo, a importância da linguagem.

Ao afirmar a necessidade de desenvolver na criança e no adolescente a observação $e$ a precisão, considerou as habilidades intelectuais envolvidas na aprendizagem, que devem ser estimuladas, tais como examinar e explicar, as quais incluem, simultaneamente, a aprendizagem do pensamento crítico que emerge do processo cognitivo e da capacidade de linguagem, e articula a relação entre pensamento e linguagem, conforme foi demonstrado, antes de Monbeig, por Piaget e Vigostki em exaustivos estudos, os quais contribuíram e contribuem ainda para o reconhecimento da importância da cultura e da sociedade no

\footnotetext{
${ }^{9}$ Pág. 16, 17 e 18.
} 
processo de desenvolvimento humano, inaugurando a perspectiva sociocultural da educação, a qual vem contribuindo para se repensar o sentido da educação escolar e refletir sobre a perspectiva tecnicista que valoriza educação relacionada à economia e reduz a importância do sistema cultural no próprio desenvolvimento da sociedade, cujas consequências já se fazem sentir no próprio desenvolvimento humano e mesmo na economia.

Quando Monbeig propõe que se trabalhe inicialmente com observação e descrição com recursos simples como carta, figura ou projeção fotográfica demonstrou compreender a progressividade da complexidade na aprendizagem de geografia que, com o passar do tempo, levará os educandos a terem condições de descobrirem e exporem as relações existentes entre diferentes fatos anteriormente conhecidos, descritos e identificados.

Reconhece assim a dimensão psicológica da aprendizagem fundada nos processos cognitivos e percebe a implicação entre pensamento e linguagem ao propor, de modo articulado, a habilidade de observação, as operações mentais de identificação e de análise, e as capacidades de linguagem envolvidas no processo de explicação, argumentação e descrição. Ao mesmo tempo, acrescenta a questão da crítica não como um conteúdo, mas como um processo interno dos indivíduos, e o qual o ensino de geografia pode apoiar dado que, do ponto de vista da aprendizagem, o aluno pode ser levado a exercitar de maneira sistemática o reconhecimento de diversas relações entre elementos diferentes e abstratos.

Monbeig apontou também com clareza que o professor de geografia precisa considerar o nível de desenvolvimento de seus alunos, não pretendendo visar em nível de educação básica a preparação de pequenos geógrafos. Assim, generalizou a questão para o currículo escolar como um todo, de modo a integrar o professor de geografia e todos os demais professores de outras disciplinas escolares na finalidade maior da educação, definindo seu papel e o caráter interdisciplinar que o currículo escolar possui quando afirma que...

[...] Sua posição [a do professor de geografia] é a mesma de todos os professores de ginásio [atualmente, ensino fundamental II], cuja missão não é recrutar especialista desta ou daquela matéria, mas de colaborar com todos os seus colegas na formação de mentes capazes de pensar e de criticar $^{10}$.

Sua problematização se assenta no entendimento de que o ensino de geografia supõe...

\footnotetext{
${ }^{10}$ Pág.18.
} 
[...] apresentar à compreensão dos alunos complexos geográficos que eles não podem compreender, a não ser por meio de um trabalho de raciocínio crítico. [...] e não convém que [o professor] fale de complexo geográfico a menos que sinta sua classe em condições de perceber-lhe o valor filosófico ${ }^{11}$.

Considera também que o ensino de geografia pode contribuir para o desenvolvimento do senso da realidade e, ao mesmo tempo, de sentimento de evolução, e compreensão da complexidade das relações. Trata-se de aprender as transformações que ocorrem no mundo identificando-Ihes os fatores e as consequências.

Outra questão contemporânea também colocada por Monbeig se refere ao enorme valor que atribuiu ao ensino de geografia para a formação da cidadania. Para o autor, os jovens alunos ou alunas de colégio estão em vésperas de se tornarem cidadãos, eleitores num grande país moderno e assim devem ter uma ideia dos problemas nacionais. Então, nas aulas de geografia, os jovens podem aprender...

[...] o que é o problema das secas ou a questão do esgotamento dos solos, pois o ensino de geografia física e o da geografia do Brasil darão ao professor a oportunidade de discuti-los. As aulas de geografia humana serão outras tantas ocasiões para facilitar o conhecimento dos problemas de imigração, de colonização, de dispersão ou de agrupamentos de populações. Serão conhecidos na aula de geografia todos os tipos humanos do Brasil, não como temas literários, mas como seres vivos em meios naturais definidos, representando papéis definidos na vida social do país, exercendo atividades econômicas diversas na economia nacional [...]. Certamente não se trata dessa caricatura de geografia econômica que consistia em enumerar os países e seus produtos, classificando estes por ordem de grandeza [...]. Referimo-nos a uma geografia econômica explicativa que, estreitamente ligada à realidade, indica problemas $e$ tendências ${ }^{12}$. (grifos nossos).

Apesar dos temas apontados no trecho citado não se apresentarem do mesmo modo em que se apresentam as temáticas e abordagens atuais emergentes na ciência geográfica ${ }^{13}$, é inegável seu empenho em explicitar os problemas de que trata a geografia quanto a seu papel e o valor intrínseco desta no currículo escolar, articulando educação e cidadania conformando a atualidade de sua problematização, inclusive pelo fato de que hoje, mesmo não sendo obrigatório, o voto aos 16 anos é uma realidade no contexto brasileiro, não sem refutações ou resistências, mas que na etapa atual vemos a predominância de determinadas

\footnotetext{
${ }^{11}$ Idem.

${ }^{12}$ Pág. 19.

${ }^{13}$ Como, por exemplo, temáticas da globalização, meio ambiente, sustentabilidade, energia limpa, práticas socioespaciais, direitos difusos, multiculturalismo, meio técnico informacional, representações cartográficas, linguagens, desigualdade social e econômica, acidentes naturais, mudanças climáticas, e etc.
} 
tendências educacionais, denominadas genericamente de tecnicistas, que não valorizam as disciplinas escolares vinculadas às ciências humanas e seu papel na formação da cidadania, especialmente, quanto à importância da educação escolar para a formação de pensamento crítico das futuras gerações conforme se pode verificar nos questionamentos colocados pelo autor quanto a

[...] onde, quando e como o jovem cidadão apreenderá o que é o problema da industrialização do seu Brasil, em que consiste seu comércio exterior, do qual depende tão perto seu nível de vida? Onde, quando e como conhecerá algo a respeito da economia de outros países, das rivalidades econômicas, dos aspectos do mundo que condicionam a vida de cada nação ${ }^{14}$ ? [grifos nossos]

Monbeig considera os contatos e as interações que as crianças e os adolescentes têm no mundo moderno que, segundo ele, necessita de um ensino moderno e a Geografia é uma interrogação permanente do mundo. Reconhecendo também a necessidade de mudanças no ensino de Geografia que acompanhem as mudanças do sentido da vida, afirma que...

[...] A conversação em família em alguns meios, o rádio, a televisão, os jornais, as atualidades cinematográficas mergulham os jovens, e às vezes até as crianças, nesse banho cotidiano de inquietação, pelo menos no que se refere aos debates econômicos. Não é difícil ao professor aproveitar-se disso para animar o seu ensino. Os alunos encontrarão aí uma prova de que a vida não para à porta da classe, a qual deixará de ser um meio artificial. A ânsia de viver dos jovens ajusta-se mal ao divórcio entre a rua e sua agitação e a escola que se esclerosa [...]. Acrescentamos ser desejável que o ensino venha esclarecer e ordenar a confusão que as informações diretas criam nos cérebros jovens ${ }^{15}$.

As questões colocadas pelo autor permanecem muito pertinentes, pois ao considerar $o$ rádio, a televisão, os jornais, as atualidades cinematográficas captou a relação entre a expansão dos meios de comunicação e o ensino, antecipando a necessidade de compreensão pela escola acerca das tendências que emergiam no mundo. Monbeig conseguiu assim, relacionar o ensino de geografia aos complexos aspectos tecnológicos, informacionais, culturais, sociais, políticos e econômicos que foram se tornando predominantes e contraditórios, os quais a ciência geográfica passou a considerar também, demonstrando ter clareza do contexto em que a sociedade e a escola estão imersos, reconhecendo as profundas implicações colocadas para o desenvolvimento das crianças e jovens.

\footnotetext{
${ }^{14}$ Pág. 20.

${ }^{15}$ Idem.
} 
Podemos considerar que teve a perspicácia de problemas que, mais recentemente, são abordados nos estudos geográficos, os quais identificam a emergência do "meio técnicocientífico-informacional" pensado como condição nova e dominante do mundo em todas as escalas, e cujas características impõem também que se repense o ensino de geografia, dado que a escola continua sendo, talvez, a única possibilidade que a criança e o adolescente, em geral, têm para aprender a pensar o mundo em que vive, podendo ter no ambiente sociocultural e tecnológico da escola a perspectiva de superar a confusão [e desorientação] que as informações diretas criam nos cérebros jovens já apontadas por Monbeig, e que se identifica também hoje em dia.

O ensino de geografia, com certeza, pode propiciar o exercício e a aprendizagem do pensamento complexo, e assim elaborar conhecimentos que, sem a escola não poderiam ser elaborados, em que pese hoje, as crianças e os adolescentes, em geral, terem acesso a qualquer informação, e muitas vezes sem mediação da família, do professor de geografia e da escola como um todo. Assim, antecipou a indicação de "novos" problemas, que ainda estão colocados para o ensino de geografia, pois informação não é conhecimento.

Pierre Monbeig também se posicionou de modo crítico acerca de aspectos cruciais que envolviam, na década de 1950, o debate educacional sobre a importância da geografia e do seu ensino, como por exemplo, os questionamentos, que permanecem ainda hoje, acerca da necessidade e validade de manutenção da disciplina de geografia no currículo escolar. A tendência de reduzir o ensino de geografia na escola afetou e fragilizou, segundo ele, a própria formação do professor de geografia como acontece atualmente também. Considerava que tal ocorria por desconhecimento, falta de entendimento e de visão por parte dos planejadores educacionais sobre a natureza do trabalho e das concepções geográficas quando afirmou...

[...] Fosse melhor o conhecimento dos trabalhos e concepções geográficas atuais e não se pensaria em reduzir o ensino da geografia e dar-se-ia mais atenção aos processos de recrutamento e formação de professores. O mal não está na disciplina ensinada, mas na forma porque é feito esse ensino, por professores cujos conhecimentos e noções teóricas estão aquém do atual estado da ciência. Se é lícito interpretar-se o pensamento dos colegas, eu diria que os geógrafos são os primeiros a desejar uma mudança no ensino de geografia, que julgam possível, entregando cada ano maior número de cadeiras a professores especialmente preparados [...]. ${ }^{16}$ (grifos nossos)

\footnotetext{
${ }^{16}$ Pág. 21.
} 
Também estabeleceu a importância da profissionalidade do geógrafo enquanto professor, destacando a relação que o profissional deve ter com o saber geográfico, cujo valor se perde pelo caráter de improvisação que cercava, e ainda cerca a prática do ensino de geografia que era, e atualmente em muitas circunstâncias, ainda é ministrado por não geógrafos. Em relação ao assunto, Monbeig é categórico quando afirma que...

[...] Ninguém pode improvisar-se professor. Salvo casos excepcionais, aquele que exerce uma certa profissão não está, só por isso, apto a ensinar uma disciplina científica, da qual nada aprendeu desde a juventude. Nenhum professor de geografia pensaria em improvisar-se engenheiro ou advogado. A recíproca deveria ser verdadeira ${ }^{17}$. (grifos nossos)

Assim, o autor contribui ainda para aprofundar a reflexão contemporânea sobre o ensino de geografia, ressaltando-se aqui a permanência do problema da formação de professores de geografia, o que se reporta ao valor e à especificidade do conhecimento geográfico na educação escolar, o qual implica diversas concepções de estudos que esta ciência recobre e que permanecem na atualidade, em que pesem as transformações que ocorrem no mundo e modificam o ensino e as próprias concepções de geografia.

Além de matéria de ensino, Monbeig considerou que a geografia é também um instrumento moderno que pode servir as coletividades públicas ou grupos privados. A pesquisa geográfica pode ser aplicada e assim como outros profissionais, sua opinião [dos geógrafos] deveria ser ouvida.

Dentre as concepções de estudo que a ciência geográfica recobria na década de 50, o autor destacou várias experiências no mundo onde tiveram e ainda se tem a participação de geógrafos, tais como a "planificação regional" na Bélgica e na Grã-Bretanha, nos Estados Unidos e mesmo na extinta URSS no pós-guerra, com ênfase na reorganização da agricultura, na localização das indústrias, no gigantismo urbano, e na forte densidade de população e grande concentração industrial.

O que nos interessa destacar aqui é que, apesar das diferenças de abordagem que caracterizam atualmente a pesquisa geográfica, os temas apontados por Monbeig demonstram a vitalidade do trabalho do geógrafo e sua importância na sociedade contemporânea, o que não era compreendido por parte da opinião pública culta na década de 50 e atualmente também, conforme ele identificou quando afirmou...

[...] Se a geografia ocupa cada vez maior lugar na administração dos países, resta ainda esclarecer a opinião pública a respeito do que pode consistir o

\footnotetext{
${ }^{17}$ Pág. 22.
} 
trabalho do geógrafo [...] Convém lembrar que em nossa época, mesmo nos países onde o liberalismo econômico e o livre empreendimento conservam seu prestígio teórico, verificou-se a necessidade de se impor uma direção geral à coletividade. [...] Deve-se isto ao fato de que, por toda a parte surgiu e se impôs o problema da organização do território da forma mais racional possível. [...] Ora, ninguém mais indicado que o geógrafo para fazer inquéritos de onde podem surgir decisões concernentes a esses problemas. Se, precisamente, o geógrafo estuda relações complexas dos meios naturais e dos grupos humanos em sua localização e em função de sua área espacial, é ele, por excelência, o técnico da organização do espaço. Mas não basta organizar o espaço, é preciso organizá-lo bem [...]. ${ }^{18}$ (grifos nossos)

O autor também aponta o sentido interdisciplinar do trabalho do geógrafo quando alerta a ausência de participação deste, cuja profissão é precisamente estudar os múltiplos laços dos inúmeros fenômenos que se relacionam à organização do espaço, o que envolve a participação de outros especialistas afirmando que...

[...] O geógrafo não é onisciente e o que lhe cabe é apenas um lugar numa orquestra, mas não é ele toda a orquestra! [...] O estudo será entregue a grupos de pesquisadores - pedólogos, geólogos, agrônomos, higienistas; outros serão economistas, sociólogos, técnicos de transportes; outros, geógrafos. A estes cabe contribuir para a harmonização dos pontos de vista dos técnicos. Seu papel será complementar, mas permite a síntese indispensável. [...] Não compete aos geógrafos nem tampouco aos demais técnicos, tomar a decisão final. Esta cabe à Política [...] A colaboração dos cientistas é informativa, mas não é uma função de comando. A pesquisa geográfica [...] pode ir até apresentar sugestões, mas a Política, que tem horizonte mais vasto ainda, deve assumir sua própria responsabilidade $e$ fazer a escolha. As competências e domínios de uns e outros avizinham-se, sem confundir [...]. Faz-se mister lembrar isso, pois bem conhecemos a forte tendência atual para dirigir a pesquisa científica tal como a grande tendência de se entregar aos técnicos a regência da vida das nações. $A$ pesquisa geográfica deve ser livre, para ser frutífera. Qual seria o valor de um inquérito sobre as possibilidades de organização da Amazônia, se ele fosse realizado por agentes que tivessem recebido diretrizes políticas favoráveis a uma conclusão orientada? Todo o organismo de pesquisa científica tem interesse em trabalhar dentro da independência científica tradicional nas universidades. Somente sob esta condição a pesquisa poderá ser útil à coletividade ${ }^{19}$. (grifos nossos).

A concepção de profissão do geógrafo que Monbeig indica é polêmica, e aponta um problema também bastante atual que se refere à formação de uma tecnocracia que se expande cada vez mais e expressa em largos aspectos, a importância dos temas relacionados

\footnotetext{
${ }^{18}$ Pág. 25.

${ }^{19}$ Pág. 26 e 27.
} 
à questão de controle e de gestão das sociedades atuais, especialmente quanto ao complexo processo de "mundialização" ou "globalização" na etapa contemporânea do capitalismo.

$\mathrm{Na}$ verdade, os referidos temas de controle e gestão das sociedades articulado com as questões da técnica e das tecnologias têm permeado o debate sobre o trabalho dos geógrafos e dos professores de geografia de modos variados e antagônicos, cujas consequências no âmbito do ensino de geografia têm contribuído para eclipsar o valor da própria geografia e do trabalho do geógrafo na esfera do conhecimento humano em geral.

Permanece comprometida a visibilidade da especificidade desta ciência no currículo escolar e sua importância na formação e desenvolvimento das futuras gerações, pois tem se realizado, muitas vezes, a transposição direta para o ensino dos debates que caracterizam as diversas concepções que são elaboradas e embasam o trabalho acadêmico e científico. Como consequência, vão se impondo à esfera escolar concepções curriculares que tem reforçado a ideia de que o conhecimento da geografia ou seria "pronto e acabado" ou "sem valor" para o desenvolvimento de funções intelectuais nos processos de aprendizagem que devem ocorrer na escolarização.

Na verdade, a especificidade da ciência geográfica necessita ser repensada também no campo da formação de professores de geografia onde se verifica uma tendência predominante de separação entre a formação do geógrafo e a formação do professor ${ }^{20}$ acarretando fragilidade intelectual na formação do último, não contribuindo para uma integração do papel do geógrafo e do professor, o que poderia tributar novas reflexões que embasariam as diversas concepções que circulam na produção do conhecimento científico e acadêmico da geografia. Na prática, o crescimento e a expansão dos cursos de licenciatura sem o bacharelado reproduz a concepção que valoriza o conteúdo em si, até como informação, enfraquecendo e esvaziando a possibilidade de na escola se trabalhar com o desenvolvimento do pensamento científico que tem em sua base a aprendizagem da reflexão e da crítica.

O ensino de geografia não tem conseguido, na verdade, desenvolver o interesse na possibilidade de apoiar a aprendizagem e o desenvolvimento das funções intelectuais implicadas nas diversas concepções que existem nas pesquisas geográficas, incluindo-se aqui a própria representação do mundo, subestimando o valor que a aprendizagem do pensamento científico da geografia e das demais ciências humanas tem para o

\footnotetext{
${ }^{20} \mathrm{O}$ que no caso do curso de Geografia na USP não ocorre conforme alternativa prevista no Programa de Formação de Professores da Universidade de São Paulo, a partir de 2006, pois a formação do geógrafo garantida no bacharelado está integrada à Licenciatura desde o início do curso.
} 
desenvolvimento sociocultural das futuras gerações que atualmente se encontram em idade escolar.

Hoje, tanto quanto no tempo de Monbeig, o ensino e a aprendizagem de geografia envolvem níveis mais altos de abstração e complexidade, o que exige também a incorporação da perspectiva psicológica e sociocultural na formação de professores de Geografia, pois a afirmação da geografia no currículo escolar consiste em afirmar seu valor quando trata dos problemas da sociedade, da realidade da vida e do mundo em que vivemos. E, segundo Monbeig...

É tal a multiplicidade dos problemas que surgem no quadro do meio atual que a contribuição de cada técnico se arrisca a cair numa especialização estreita, às vezes esterilizante. Pela largueza de seus pontos de vista, o geógrafo completa os técnicos. Os problemas que ele pode ajudar a resolver mais se evidenciam num país como o Brasil, onde há tantas áreas para organizar, onde tantas possibilidades restam a explorar, onde tanto dinamismo se gasta em tantas direções contraditórias ${ }^{21}$.

Cabe assinalar e destacar ainda a compreensão humanista que Monbeig tem sobre a geografia e seu significado no ensino quando afirma que...

[...] Graças ao seu campo de estudo, ao seu método de trabalho, a geografia tem lugar no ensino. Tem-no por ser uma ciência moderna, produto do mundo atual tal como aquele em que vivem os jovens. Ela desenvolve neles as qualidades intelectuais ou morais e dá-lhes conhecimento dos mais úteis para o pleno desenvolvimento de suas personalidades no quadro em que devem desabrochar. A geografia é uma das formas do humanismo moderno ${ }^{22}$.

A posição de Monbeig alerta, entre outros aspectos, para a importância da geografia como uma ciência moderna no currículo escolar. Sem entrar aqui nos dilemas e reflexões sobre a modernidade, observamos que em sua compreensão, está presente a afirmação e valorização das formas do humanismo moderno. Esta afirmação é muito significativa se considerarmos o caráter tecnicista, utilitário, fragmental e pragmático que vem predominando no debate educacional contemporâneo, no qual se estabelece uma relação direta entre ensino e economia, subordinando as perspectivas da educação escolar a interesses imediatos, específicos e particulares que não levam em consideração a perspectiva sociocultural e a necessidade do desenvolvimento humano, que são de interesse comum a toda sociedade.

\footnotetext{
${ }^{21}$ Pág. 27.

${ }^{22}$ Pág. 21.
} 
Sua visão de geografia contribui para enriquecer diversas tendências contemporâneas que consideram a possibilidade de se pensar o ensino orientado por conhecimentos mais "produtivos" do que "reprodutivos" e assim contribuir para uma educação mais prospectiva do que retrospectiva no sentido de se ensinar aos estudantes um modo específico de aprender a identificar problemas que ocorrem na vida social e no mundo, bem como resolvê-los, e resolvendo-os para aprender a solucionar problemas. Em última instância, o ensino de geografia como um humanismo moderno também recoloca a importância das ciências humanas para o desenvolvimento de funções intelectuais e habilidades gerais de crianças e adolescentes que se encontram em diferentes etapas do seu desenvolvimento potencial.

Refletindo acerca do sentido humanista da geografia que encontramos em Monbeig, encontramos também em Paul Claval a reafirmação deste sentido quando tratou da importância do ensino de geografia na atualidade, considerando que...

[...] se nossas sociedades estão desamparadas, é porque a Geografia não foi ensinada como deveria ter sido: não é a ela que cabe fazer todos compreenderem como se construiu a Terra dos homens e em quais condições ela pode continuar a sê-lo ${ }^{23}$ ?

Finalmente, nesta breve reflexão acerca da contribuição de Pierre Monbeig para a reafirmação contemporânea da importância do ensino de geografia no currículo escolar, destacamos o "direito a aprender geografia" quando afirmou que...

[...] Reconhecido o valor formativo da geografia, e lembrando-se que os programas de países como os Estados Unidos, Inglaterra, França ou Alemanha não o reduzem, é lógico pensar que os jovens brasileiros também merecem receber este ensino; todavia, tem o direito de recebê-lo em boas condições. (grifos nossos) ${ }^{24}$.

Visando apenas refletir sobre o problema já colocado por Monbeig, em 1956, do direito a aprender geografia em boas condições, assinalamos a necessidade de especial atenção de toda a comunidade de geógrafos e professores de geografia para o fato de que, atualmente, parece despercebida, no contexto dos debates sobre os dilemas educacionais brasileiros, a tendência crescente de pensar o currículo escolar, priorizando-se a "quantidade de disciplinas" em detrimento da "qualidade" e das condições do ensino destas.

Está presente atualmente a iminência de se reinaugurar, a possibilidade de supressão, substituição ou diluição de disciplinas no currículo como se isso resolvesse os problemas do

\footnotetext{
${ }^{23}$ IN: CLAVAL, Paul. Terra dos Homens - a geografia. Editora Contexto, São Paulo, 2010. pp. 137.

${ }^{24}$ Pág. 21.
} 
ensino e da educação escolar tal como a reforma educacional promovida pelo regime militar a partir de $1964^{25}$.

Naquela época prevaleceu, autoritariamente, um modo de pensar que descaracterizou a importância da Geografia, e por que não dizer da História também, como disciplinas autônomas, que foram reduzidas a Estudos Sociais. O que difere na abordagem atualmente é a ênfase que está sendo dada às áreas do currículo para reorganizar o ensino, e não mais às disciplinas com origem na tradição histórica, científica e acadêmica, sob o pretexto de atualizar o currículo escolar pela superação do "excesso" de disciplinas e a especialização/fragmentação que estas impõem ao currículo.

Diante deste quadro, avistam-se mais consequências negativas para a formação de professores e para o desenvolvimento do pensamento crítico e reflexivo das futuras gerações, aliás, como já aconteceu anteriormente.

Na verdade, pensamos que é urgente repensar o valor do ensino de geografia, pois esta ciência tem se firmado como ciência moderna, como nos colocou Monbeig, comprometida com os acontecimentos do mundo, da vida e da sociedade na perspectiva do desenvolvimento humano, conforme aponta também Edgar Morin, quando considera que estamos vivendo um momento em que é necessário "religar os saberes", o que não quer dizer substituí-los ou suprimi-los, mas...

[...] Trata-se de um ponto que se encontra igualmente ausente do ensino e que deveria ser considerado como essencial: a arte de organizar seu próprio pensamento, de religar e, ao mesmo tempo diferenciar. Trata-se de favorecer a aptidão natural do espírito humano [de] contextualizar e [de] globalizar, isto é, [de] relacionar cada informação e cada conhecimento a seu contexto e conjunto. Trata-se de fortificar a aptidão [para] interrogar e [para] ligar o saber à dúvida, de desenvolver a aptidão para integrar o saber particular em sua própria vida e não somente a um contexto global, a aptidão para colocar a si mesmo os problemas fundamentais de sua própria condição e de seu tempo ${ }^{26}$.

\section{REFERÊNCIAS BIBLIOGRÁFICAS}

\section{CHARLOT, B. Relação com o Saber: Formação dos Professores e Globalização: questões} para a educação hoje. Porto Alegre: Artmed, 2005.

\footnotetext{
${ }^{25}$ Refiro-me aqui à Reforma consubstanciada pela Lei 5692/71 em que houve a criação do Ensino de 1 o grau de 8 anos, o qual tomou o lugar dos antigos ensino primário e ginasial; e, a criação do Ensino de 2 o grau que tomou o lugar do ensino colegial de 3 anos que passou a ser técnico profissionalizante. A par disso, também foram suprimidas no Ensino de 1으 grau as disciplinas de Geografia e História, tomando seu lugar as disciplinas de Estudos Sociais, Educação Moral e Cívica e Organização Social e Política do Brasil.

${ }^{26}$ MORIN, Edgar. A Religação dos Saberes - O desafio do século XXI. Bertrand Brasil. Rio de Janeiro. 2007. pp. 21.
} 
CLAVAL, P. Terra dos Homens - a geografia. São Paulo: Editora Cortez, 2010.

DAVIDTS, J. A Volta do Pequeno Príncipe. Rio de Janeiro: Ediouro, 1999.

HARgReAVES, A. Professorado, cultura y postmodernidad - Cambian los tiempos, cambia el professorado. Madrid: Ediciones Morata, 1999.

JAPIASSU, H. A crise das Ciências Humanas. São Paulo: Cortez Editora, 2012.

KOZULIN, A. Instrumentos Psicológicos - La educación desde uma perspectiva sociocultural. Barcelona: Ediciones Paidós Ibérica S.A, 2000.

MORIN, E. A cabeça bem-feita - repensar a reforma, reformar o pensamento. Rio de Janeiro: Bertrand Brasil, 2008.

A Religação dos Saberes - O desafio do século XXI. Rio de Janeiro: Bertrand Brasil, 2007

MONBEIG, P. Papel e Valor do Ensino da Geografia e de sua Pesquisa. IBGE - Conselho Nacional de Geografia, Rio de Janeiro. 1956.

MOREIRA, R. O pensamento geográfico brasileiro - as matrizes brasileiras. São Paulo: Contexto, 2010. v. 3.

PIAGET, J. A situação das ciências do homem no sistema das ciências. Lisboa: Livraria Bertrand, 1976.

POZO, J. I. (org.) A solução de Problemas - Aprender a resolver, resolver para aprender. Porto Alegre: Artmed, 1998.

SANTOS, M. A Natureza do Espaço - Técnica e Tempo, Razão e Emoção. 5 ed. São Paulo: Edusp, 2002.

VIGOSTKI, L. S. A construção do pensamento e da linguagem. São Paulo: WMF Martins Fontes, 2009. 